\title{
El diálogo entre terapia ocupacional y filosofía en torno al problema del existir desde el pensamiento de Heidegger
}

\section{The dialogue between occupational therapy and philosophy around the problem of existence in Heidegger}

Marjorie Schliebener (marjorie.schliebener@mayor.cl) Escuela de Terapia Ocupacional, Universidad Mayor (Temuco, Chile) ORCID: 0000-0001-7078-7759

\begin{abstract}
This paper aims to emphasize the current need for occupational therapy to have a dialogue with philosophy, to highlight the question concerning the human being as occupation. The article argues that occupational therapy could be in a crisis concerning its fundamental grounds that, on the one hand, guide it and, on the other hand, give it sense to its own practice, proposing as a possible answer following Martin Heidegger's analytics of Dasein. In this context, we will try to clarify why and how the phenomenon of occupation can be considered as an essential and constitutive moment of each human person.
\end{abstract}

Key words: human being, occupation, occupational therapy, analytics of Dasein, philosophy.

\section{Resumen}

En el presente trabajo intentaremos destacar la necesidad que existe hoy, para la terapia ocupacional, de entablar un diálogo con la filosofía, enfatizando la relevancia de plantear la pregunta concerniente al ser humano en cuanto ocupación. Se plantea que la terapia ocupacional se encontraría en una situación de crisis de los fundamentos que la orientan y le brindan sentido a su práctica, proponiendo como posible solución una revisión de los aspectos principales de la analítica del Dasein de Martin Heidegger, con el objeto de clarificar por qué y cómo el fenómeno de la ocupación puede ser considerado como un momento constitutivo de cada existencia humana.

Palabras clave: ser humano, ocupación, terapia ocupacional, analítica del Dasein, filosofía.

\section{Introducción}

La terapia ocupacional requiere preguntarse en cada momento sobre la dirección que ha ido tomando. Esto lo podemos ver en su propia historia. Así, a comienzos del siglo XIX, en Estados Unidos, un grupo de profesionales de la salud, entre ellos médicos y enfermeras, aplican principios humanistas en la atención de sujetos que padecían diversas patologías, fundando una nueva disciplina socio-sanitaria llamada "terapia ocupacional". Aquí ya se afirmaba que "corresponde a la naturaleza humana el desempeño de alguna ocupación" (Kielhofner 2006:34). 
Luego, a fines de la década de los 40s, la terapia ocupacional sufre una crisis a partir de la presión por la validación de su hacer dentro del campo de la medicina, por lo que sucumbió a enfoques mecanicistas que la llevaron a practicar técnicas centradas en la recuperación de los signos y síntomas propios de cada patología. De esta forma, "el pensamiento holístico fue reemplazado por el énfasis reduccionista en los trabajos internos de la psique y del cuerpo humano" (Kielhofner 2006:56), desconociendo la misión original que la terapia ocupacional, en sus inicios, se habría propuesto, esto es, la consideración de la naturaleza ocupacional de los seres humanos y la importancia de la ocupación en la obtención de mayores niveles de salud.

Más tarde, en la década de los 60s y 70s, surge una segunda crisis, donde se trata de retomar los principios y valores fundantes de la terapia ocupacional. Se hace el llamado a recuperar la práctica centrada en la ocupación y a dejar atrás el enfoque biomédico que dominaba en ese entonces. Así, se desarrolla en la disciplina una nueva refundación bajo los principios que impulsaron su creación. Si bien, esta visión es la que debería mantenerse hasta el día de hoy, cada vez aparecen con más fuerza influencias desde las ciencias sociales en el campo de la terapia ocupacional, surgiendo la llamada terapia ocupacional social o política, con fundamentos desde paradigmas críticos. Asimismo, se incorporan teorías que llaman a considerar la centralidad de la cultura y el contexto socio-histórico en el ejercicio de la disciplina. Actualmente, en Chile, a esta nueva corriente se la ha denominado "Paradigma Social de la Ocupación" (Morrison, Olivares y Vidal 2011:13).

Estas nuevas miradas exploran en comprensiones mucho más amplias y complejas acerca de cómo la terapia ocupacional debería considerar la noción del ser humano y su mundo. Es así como se establecen entendidos acerca de la ocupación humana como eminentemente social y política. Si bien estos enfoques sitúan al sujeto ocupado en un contexto económico, político y cultural, en tanto productor y reproductor de sociedades, con la capacidad de generar proyectos de vida entendiendo las limitaciones contextuales de la realidad actual, sin embargo, hace falta un abordaje aún más radical, que tendría como tarea profundizar en la comprensión del sujeto de intervención de la terapia ocupacional, esto es, el ser humano, desde un carácter esencial, que nos permita conocer originariamente cómo es que es posible una noción de ser humano en una relación inseparable con el mundo y cuál sería, entonces, el rol de la ocupación en esta consideración.

En este sentido, Alejandro Guajardo menciona que la ocupación no es una "manifestación de una interioridad intrínseca, sino más bien un proceso que se expresa 'como ser-en-el-mundo', como actividad de vivir en el mundo" (Guajardo 2011:16), planteando la posibilidad de dar un paso aún más radical y que sería el de ubicar el problema de la ocupación "en el orden del fundamento, en el ser, que es lo real" (Guajardo 2011:16). En este sentido, la tarea debería estar centrada, entonces, en el terreno de la ontología, en tanto que se preocuparía de la pregunta por la ocupación como un aspecto esencial del ser humano.

Asimismo, Da Rocha Medeiros (Terapia Ocupacional: un enfoque epistemológico y social) también coincide con Guajardo en relación con la necesidad que se manifestaría en la terapia ocupacional de discutir y aclarar qué es el hombre, el mundo y los valores que se verían implicados en su propia existencia, a partir de los conflictos que se han generado en la disciplina debido a la convivencia de diversos modelos que buscarían guiar su praxis. En este sentido, y como lo comenta la autora, un cuestionamiento de los fundamentos de la terapia ocupacional implicaría ubicarse en el terreno de la filosofía, dado a que los 
problemas advertidos, al parecer, tendrían relación con la manera cómo comprendemos al ser humano y su mundo.

También Ann Wilcock, una de las grandes representantes de los estudios sobre ocupación humana en el campo de la terapia ocupacional, declara que "cada persona piensa y actúa de acuerdo a una visión personal de naturaleza humana, pero raramente se intenta articular o probar esta visión, en lugar de eso, prefieren afirmar lealtad a una visión sociocultural aceptada" (Wilcock 2006:52). Aquí Wilcock da cuenta de la escasez de intentos por profundizar en las comprensiones de naturaleza humana dentro del ámbito de los estudios sobre ocupación, siendo una de las motivaciones que le impulsan a desarrollar su Teoría de la Naturaleza Ocupacional del Ser Humano.

De esta forma, reconocemos el llamado que hace Guajardo, De Rocha Medeiros y Wilcock, y que se centra en asumir la tarea de repensar al ser humano y la ocupación, con el propósito de generar nuevas orientaciones que permitan una consolidación de la identidad de la terapia ocupacional, a partir de una revisión de sí misma y de las diversas orientaciones que hasta el momento conviven en ella.

Podemos preguntar por qué sería pertinente detenernos en la búsqueda de nuevas orientaciones en terapia ocupacional con el fin de fortalecer su propia identidad. Consideramos que resulta necesario, en el campo de los fundamentos de la terapia ocupacional, profundizar en la comprensión que se tiene acerca del hombre y su mundo, ya que esto determinaría el trato con éste y, a la vez, los modos de abordaje terapéuticos.

Pero dónde buscar nuevas perspectivas. Si el llamado de estos reconocidos terapeutas ocupacionales es pensar el hombre en términos filosóficos, entonces, el propósito sería comprender cómo es que la ocupación es una dimensión esencial de su propio existir. Esto implica que la búsqueda de nuevos horizontes, que delimiten la identidad de la terapia ocupacional, consistiría en un diálogo con la filosofía. Ciertamente, a lo largo de la historia de la terapia ocupacional esto, en efecto, se ha hecho, mas no desde enfoques estrictamente existenciales, es decir, referidos a la relación más radical del ser humano con el mundo en su más pura cotidianidad. Y justamente, a nuestro juicio, es un diálogo con un tipo de filosofía que acentúe este carácter existencial el que puede abrirnos a estos nuevos horizontes. Por nuestra parte sugerimos una revisión de la ocupación humana desde la perspectiva existencial de quien abriera este tipo de enfoque para abordar al ser humano: Martin Heidegger. De este modo, iniciaremos nuestra búsqueda a partir de la analítica existencial del Dasein, ya que, como se advertirá en este estudio, sus planteamientos existenciales pueden ser muy significativos para hallar soluciones fructíferas a las interrogantes que aquí se plantean en el contexto del problema de la ocupación, en el ámbito de la terapia ocupacional.

A continuación, entonces, indagaremos en los fundamentos de la ocupación humana, entendida ésta como estructura fundamental del existir, en el contexto del programa de Heidegger temprano y además de las lecciones que se encuentran en la órbita de Ser y Tiempo, todo con el fin de atender a la siguiente pregunta: cómo es el diálogo entre la terapia ocupacional y filosofía en torno al problema del existir desde el pensamiento de Heidegger. De este modo, y con el fin de comprender el sentido en el que se mueve el fenómeno existencial de la ocupación, abordaremos previamente la noción de Dasein, mundo $y$ mundaneidad y, finalmente, cuidado, en el contexto de la analítica existencial que Heidegger plantea. Explorar en dichas comprensiones nos permitirá entender a la ocupación en cuanto movimientos direccionados hacia la concreción de nuestras posibilidades de ser. 


\section{Aspectos fundamentales de la analítica existencial del Dasein}

Frente a la pregunta "¿qué es el Hombre?", posiblemente podamos esbozar múltiples respuestas, como, por ejemplo, que sea éste un "ente" racional, político, cultural, etc. Pero frente a esta multiplicidad de respuestas, difícilmente reparamos en el a priori que subyace ocultamente en la pregunta, y que es la pregunta misma por el "ser". En otras palabras, el hecho de establecer que el ser humano "sea" "racional" o "político", supone desde ya una clara comprensión de "ser".

Con respecto a la pregunta por el ser y su sentido, Heidegger menciona que ésta es la más universal de todas las preguntas, pero que a lo largo de la historia del pensamiento podría haber resultado ser, al mismo tiempo, la más vacía y, como comentábamos más arriba, esto le llevaría a sostener que el ser mismo habría caído en el olvido. Dicha aseveración parte desde el entendido que las respuestas a las interrogantes que involucran la pregunta por el ser y su sentido, han carecido de determinación. Es más, Heidegger pareciera criticar, como lo hace notar Edith Stein, la misma forma en que la pregunta se ha planteado, debido a tres prejuicios específicos que han incidido en la manera como el problema del ser se habría abordado en la tradición filosófica.

El primero es que el "ser" se ha considerado como un "universal", en cuanto dicho concepto se encuentra implícito en la pregunta acerca de cualquier ente. Sin embargo, su profundización no ha sido suficiente, a pesar de la multiplicidad de categorías con las que se le ha relacionado en la historia de la filosofía. Al respecto, Heidegger menciona que no por ser "universal", ha tenido que ser el concepto más claro. Al contrario, Heidegger llega a afirmar que ha sido el más "oscuro".

El segundo prejuicio del concepto de "ser" es que es "indefinible", ya que se concluye que tendría una "suprema universalidad" (Heidegger 2012:24). Si bien, al ser se le ha considerado como algo diferente a un ente, éste "no es derivable definitoriamente desde conceptos más altos, ni puede ser explicado mediante conceptos inferiores" (Heidegger 2012:25), entendiendo que es el ente el punto de partida para definir lo "alto" o "superior", así como también lo "inferior". En este sentido, el hecho de que el "ser" no sea definido como un ente, no aclara lo que positivamente sí es como tal.

El tercer y último prejuicio, radica en que el "ser" sería un concepto evidente por sí mismo, ya que cotidianamente cualquier persona podría comprender fácilmente la expresión "el sol es amarillo" o "yo soy mujer". Sin embargo, esto no podría significar más que una comprensión vaga, por lo que podría tratarse más bien de una incomprensión del tema y, en consecuencia, daría cuenta de una suerte de renuncia a la pregunta que subyace en tales expresiones, a saber, la pregunta por aquel a priori implícito que, para Heidegger, conduce a una comprensión de ser en general que estaría en nosotros cada vez que las formulamos. Al respecto, Edith Stein (La filosofía existencial de Martín Heidegger) comenta que, según Heidegger, los intentos más importantes en la formulación de la pregunta por el "ser" fueron realizados por Aristóteles y Platón, pero que sus estudios se detuvieron en que el "ser" era el mero "estar-ahí", y desde aquí sus postulados se mantuvieron vigentes incluso en Descartes y Kant. Este comentario nos ayuda a comprender el "olvido" de la pregunta por el ser que Heidegger pretende denunciar al comienzo de Ser y Tiempo. En este mismo contexto, Alejandro Vigo (2006) menciona que para Heidegger no estaba resuelta la consideración ontológica de la noción de "ser", razón por la cual el filósofo decide recuperarla en el más amplio sentido, que ya estaba presente en la tradición filosófica griega. 
Como se ve, dichas consideraciones parecen motivar a Heidegger a subrayar la importancia de la pregunta por el "ser", ya que "repetir la pregunta por el ser significa: elaborar de una vez por todas en forma suficiente el planteamiento mismo de la pregunta" (Heidegger 2012:25). En efecto, este "repetir" la pregunta por el "ser", para Heidegger, tiene dos tipos de primacías, una ontológica y una óntica.

La primacía ontológica reside en la crítica de que toda ontología es vacía, independiente de la cantidad y riqueza de categorías que utilice, si es que no ha aclarado la noción de "ser" y su sentido, además de no reconocer a estos respectos como su misión fundamental. En este contexto, si la ontología tuviera el propósito que Heidegger devela, sería la antecesora de cualquier tipo de investigación en las diferentes regiones del saber.

Por otra parte, la primacía óntica radica en que el Dasein es el ente que a "lo somos cada vez nosotros mismos" (Heidegger 2012:63), teniendo una relación de "ser" con su "ser" (Heidegger 2012:32). Los modos de comportarse de este ente corresponden a la existencia, siendo posibilidades de ser sí mismo o no. Esta relación de la existencia con el ser del Dasein, en la que más adelante se profundizará, es de carácter óntico.

Estos dos ámbitos de primacía, tanto óntica como ontológica, ponen de manifiesto aquella radicalidad a la que Heidegger se refiere al momento de lograr mostrar una comprensión del Dasein como tal, a partir de la pregunta por el sentido del "ser". Al respecto, Vigo menciona que, en efecto, Heidegger "no pregunta, sin más, por el ser (Sein) sino, más bien, por el sentido del ser (Sinn von Sein)” (Vigo 2006:53).

Si bien, la necesidad de replantear la pregunta por el "ser" no es central en nuestro estudio, sí es necesario dar cuenta de los orígenes de la motivación de Heidegger por volver a plantearse dicha pregunta en dirección hacia la comprensión de una analítica existencial. En las palabras del autor, "la posibilidad de llevar a cabo la analítica del Dasein depende también de la previa elaboración de la pregunta por el sentido del ser en general" (Heidegger 2012:34).

Es de esta forma que el origen de la analítica existencial de Heidegger descansa en la pregunta por el sentido del "ser", y lo que debiera ser interrogado para acceder a la respuesta es el ente que tiene el carácter de Dasein. Este ente fundamental para una analítica existencial deberá ser comprendido como aquel que "somos cada vez nosotros mismos" (Heidegger 2012:63), en tanto que "el ser de este ente es cada vez el mío" (Heidegger 2012:63).

\section{El Dasein como estar-en-el-mundo}

Para continuar, debemos detenernos en lo que significa la noción de Dasein y su sentido. Tal como lo señala Heidegger "una analítica del Dasein debe constituir, pues, la primera exigencia que plantea el desarrollo de la pregunta por el ser" (Heidegger 2012:37). Ciertamente, aquí el filósofo no refiere al concepto "ser" como el "ser individual de cada uno", sino que su "pregunta por el ser" apunta a la aclaración del concepto filosófico por excelencia: comprender la esencia de todo lo que es. Y sería en este contexto que el ser tan particular como es el del ser humano, el Dasein, se presenta como el ámbito auténtico para su respuesta. Así es como indagar en lo que somos, en el caso de Heidegger, se desarrollará "en la línea de una ontología fundamental" (Heidegger 2012:151). Ahora bien, en el marco de esta pregunta tan importante para la filosofía, el pensador alemán sí aclara aspectos particulares de nuestro 
existir humano que resultan valiosos para la discusión de la terapia ocupacional y son justamente ellos los que quisiéramos esbozar a continuación.

Pero cómo podemos acercarnos a la comprensión de nosotros mismos en el marco de las investigaciones heideggerianas. Para ello debemos comenzar con la siguiente afirmación: "Dasein significa: estar-en-elmundo" (Heidegger 2008:28). Heidegger señala que "el Dasein es el mío cada vez en esta o aquella manera de ser" (Heidegger 2012:64) y además destaca que "el Dasein es el ente que yo mismo siempre soy, en cuyo ser participo yo en cuanto ente; un ente que es-siempre a mi manera-serlo" (Heidegger 2006:191). Esta mención al Dasein de que su ser "es cada vez el mío" quiere decir que nuestros modos de ser siempre parten desde la comprensión de nosotros mismos y no como algo que está ahí, lejano, entre las cosas del mundo, ya que el mundo se despliega desde nuestro propio ser, por lo tanto, nos afecta, porque somos nosotros mismos proyectando nuestro mundo en cada ocasión. En este sentido, Basso explica que el Dasein "experimenta el mundo a través de sí mismo en la forma del 'yo soy', cada acontecimiento es suyo y sus vivencias refieren indefectiblemente a ese sí mismo" (Basso 2014:276).

Ahora bien, si consideramos que el Dasein es él mismo, pues también él será el método, ya que "su ser consiste precisamente en ser en camino hacia él mismo, es decir, en la posibilidad de ser en una comprensión y mostración de él como él mismo y a partir de él mismo" (De Lara 2008:251). Es de esta forma que el Dasein, en cada modo de ser, "se relaciona con su propio ser no como frente algo presente y concluso, sino como frente a una posibilidad" (Cataldo 2013:36), siendo cada vez la posibilidad de ser él mismo, y no nos referimos a una posibilidad que se pueda adjudicar o no en algún momento u otro, sino que él es en su posibilidad más propia: "el Dasein se determina cada vez como ente desde una posibilidad que él es" (Heidegger 2012:65) y esta posibilidad puede ser tanto desde la propiedad o la impropiedad. Por posibilidad "propia" se entenderá aquel modo de ser en el que el Dasein se elige a sí mismo o que se despliega como "suyo"; en cuanto "impropia", se comprenderá aquella posibilidad "perdida" o alejada de esta mismidad. Sin embargo, en cualquier tipo de manifestación de estas posibilidades, el Dasein expresa su carácter de "ser cada vez él mismo". Es así que el Dasein "es" en un "siendo nosotros mismos en cada ocasión", "existe" en su vivir fáctico. Esta aclaración correspondería formalmente a la comprensión existencial del Dasein y que Heidegger define como: "Ente que es [y que ha de serlo] siéndolo-en-cadaocasión" (Heidegger 2006:192).

Dicho carácter de "en-cada-ocasión", que, como ya se ha aclarado, es el modo de ser de la facticidad, corresponde a la "ocasionalidad". Esta caracterización es constitutiva e inherente del Dasein, en otras palabras, no existe Dasein sin su sentido de "ocasionalidad", no hay Dasein sin su carácter de vivir fáctico. En este contexto, y debido a este "siéndolo-en-cada-ocasión", es que el Dasein, como un "ser posible", puede presentar múltiples formas de ser, en tanto posibilidades se le presenten, pero no por esta condición deja de ser Dasein.

Ahora bien, el acceso al modo de entender al Dasein no puede seguir el camino de obtener una descripción de su aspecto o de qué elementos está hecho, de cuáles son sus partes o su forma. Dedicarnos a esta tarea nos alejaría del sentido mismo del Dasein, separándonos del cometido de comprender aquello que hace que el Dasein "sea" él mismo. En este sentido, de lo que se trata es explorar en el cómo de su "ser", independiente de los posibles atributos que éste pueda adquirir o no en su "cada-vez-siéndolo". Solo de esta forma accedemos a los caracteres de "ser" del Dasein, previo a cualquier tematización de él, dicho en palabras de Heidegger: "no vamos a determinar cuál sea el aspecto de tal ente, sino que desde un principio 
y en todo momento nos vamos a ocupar únicamente de su manera de ser; no de qué esté hecho, sino del cómo de su ser y de los rasgos de ese cómo" (Heidegger 2006:194).

Como podemos ver, la tarea es entender al Dasein en su manera de ser. Pero cuál es el camino que conduce al logro de este objetivo. La tesis de Heidegger radica justamente en un llamado a poner atención en la cotidianidad más inmediata, es decir: "atender" o "considerar" al "Dasein fáctico en el cómo de su 'serlo' fáctico" (Heidegger 2006:194). Nuevamente es necesario aclarar aquí que este giro a la cotidianidad inmediata no mienta un relato de cómo ésta es vista particularmente, sino que hay que concentrarse en el cómo ella se despliega en vida fáctica, en su manera de ser "facticidad". Una referencia a este carácter del cómo sería, por ejemplo, hablar de la "lapicidad del lápiz", en tanto no lápiz grafito, de tinta o de gel, sino que en lo que hace que el lápiz "sea" eso "siéndolo siempre en cada ocasión", en cada diferente posibilidad de ser.

Hasta aquí se ha hablado acerca del Dasein y su despliegue en el vivir fáctico, expresado en un "siéndolo cada vez el mío" que da cuenta de su carácter de ocasionalidad, pero quizás estas consideraciones podrían llevar a entender que nociones tales como "vida fáctica" u "ocasionalidad" son aspectos característicos, cada uno por su parte, del Dasein, a la manera de una sumatoria de propiedades del mismo. Sin embargo, esto no parece representar las pretensiones heideggerianas. Así, se hace necesario considerar el carácter de enteridad del Dasein, con el objeto de seguir precisando qué es lo que Heidegger entendería por este modo de ser y, por cierto, por lo que él llama "analítica existencial", que es el modo como habría que exponer aquellos rasgos fundamentales que le caracterizan.

Al respecto, en el $\S 39$ de Ser y Tiempo, Heidegger menciona que "la multiplicidad fenoménica de la constitución de este todo estructural [el Dasein] y de su modo de ser cotidiano puede fácilmente obstruir la mirada fenomenológica unitaria hacia el todo en cuanto tal" (Heidegger 2012:199). Esta aclaración menciona que no se deben descomponer ni desarticular los momentos estructurales del Dasein, a modo de "partes" que se ensamblen. Por lo que cada vez que alguno de estos momentos que Heidegger pone de relieve sea explorado, en vías a una comprensión de Dasein, siempre debe considerarse que se está hablando de un todo. En palabras de Heidegger, lo que estaría en juego es una "mirada completa que atraviesa este todo en busca de un fenómeno originariamente unitario, que ya está presente en el todo y que funda ontológicamente cada uno de los momentos de la estructura en su posibilidad estructural" (Heidegger 2012:200). Sin embargo, que se esté aludiendo a una interpretación unificadora no quiere decir tampoco que, porque presenta un carácter unitario, se obvie la multiplicidad de su estructura, al estilo de "el todo es más que la suma de sus partes". En palabras de Dastur, "la multiplicidad de los momentos, lejos de ser excluida es, por el contrario, requerida por la unidad estructural del ser del Dasein y la totalidad 'indivisible' que forma como todo estructural articulado" (Dastur 2006:51). Es de esta forma que este carácter unitario es intrínseco y trascendental.

Como se ha mencionado al comienzo de este apartado, Dasein ha sido relacionado con "ser-en-el-mundo", como una estructura ontológica de éste, con el carácter de originario, total y unitario. Esto quiere decir que jamás el Dasein pierde su enteridad, ya que precisamente no está constituido por partes, sino que de "momentos" que se disponen como inseparables cada uno del otro. Estos "momentos" corresponderían a los "existenciarios" que, a su vez, pertenecen a los caracteres ontológicos fundamentales del Dasein, y que, articulados, dan forma a su propia totalidad. 
Es en este contexto que, con el propósito de avanzar en nuestras pretensiones, corresponde detenernos ahora en la noción de mundo en tanto mundaneidad, como el lugar en el que nos ocupamos, ya que la ocupación en un mundo debe ser entendida como un aspecto esencial de la estructura existencial del Dasein.

\section{La mundaneidad del mundo como estructura fundamental del Dasein ocupado}

Cuando Heidegger habla de mundaneidad lo que intenta es develar el carácter esencial de mundo. Con dicho término se aludiría a un "concepto ontológico que se refiere a la estructura de un momento constitutivo del estar-en-el-mundo" (Heidegger 2012:86) y que, a su vez, determina existencialmente al Dasein como esencialmente "mundano". En este contexto, "mundo" corresponde a "aquello en lo que vive" (Heidegger 2012:87) el Dasein fácticamente. En este sentido, Heidegger afirma que el ente más inmediato para el Dasein es el del mundo circundante (Umwelt), que referiría a "la manera en que opera el contexto de las actividades cotidianas. Se trata de la siguiente estructura: el agente de experiencia está absorto en sus ocupaciones, en medio de las cosas, inmerso en su circunstancia" (Heidegger 2012:92).

De este modo, en dicho mundo circundante, "llamaremos al ente que comparece en la ocupación el útil [Zeug]" (Heidegger 2012:90). Éste corresponde a lo que primeramente se presenta en la cotidianidad, apareciéndose como tal en tanto mantenemos un trato inmediato con él, esto es, a través de distintos modos del ocuparse. Es de esta forma que el Dasein más inmediato se encuentra, siguiendo a Heidegger, en un determinado contexto de ocupaciones, por ejemplo, escribir un texto. Es así que el ente al que podríamos concebir como una cosa, en tanto objeto "lápiz", comparecería primariamente en una "ocupación" específica como un útil para escribir. Solo en esa ocupación el lápiz sería él mismo. Con esta expresión, se deja inmediatamente de lado cualquier concepción del ente intramundano, es decir, de las cosas del mundo, como cosas objetuales desligadas de cualquier ocupación.

En este sentido el útil nunca será un ser en sí mismo, sino que es útil en tanto "algo para...", siempre en el contexto de un "hallarse ocupado". Este "para algo" expresa un carácter de remisión al modo de "algo para algo", según el cual aparecería el ente intramundano que circunda al Dasein, dicho carácter de ser de tal ente correspondería a su mundicidad (Weltmässigkeit). En este contexto Rivera, en una de las notas aclaratorias en su traducción de Ser y Tiempo, destaca que mundicidad "es el carácter perteneciente al mundo que tienen los entes intramundanos", en cambio mundaneidad "es el carácter de mundo que tiene el mundo" (nota de Rivera en Heidegger 2012:464), es decir, la esencia del mundo, a la cual nos referiremos más delante como significatividad.

Luego de esta aclaración, y para continuar en torno al "algo para algo", un lápiz vivido cotidianamente no es tal sin una hoja para escribir, una goma para borrar, etc. En otras palabras, el útil siempre se nos muestra según un "para qué" está dispuesto, y no como un mero objeto. Un vaso, por ejemplo, en este ámbito cotidiano que Heidegger destaca, se mostraría como un "para beber", pero no como una "cosa vaso" a la que le agrego la utilidad de beber. Por lo tanto, las apariciones cotidianas de las cosas del mundo no pueden sino darse en una relación del Dasein con su mundo en la cual éste esté siempre descubriendo su utilidad. Esta relación del Dasein que siempre descubre utilidad es lo que Heidegger llama "ocupación". Al respecto, el filósofo aclara que "hay en la cotidianidad del estar-en-el-mundo modos de ocupación que hacen comparecer al ente [el útil] sobre el que recae el ocuparse de una manera tal que en él se manifiesta la mundicidad de lo intramundano" (Heidegger 2012:94). 
Lo importante es destacar que esta concatenación de "para qué", que constituye al mundo, la llamada totalidad respeccional, finaliza con la pretensión de cuidarse a sí mismo, siendo éste su sentido último. Heidegger lo denominará un "por-mor-de" (Heidegger 2012:105) del mismo Dasein. Podríamos tomar el caso de martillar para clavar y después clavar para reparar el techo. Como se advierte, esta concatenación conducirá, finalmente, a un último "para qué" que sería proteger la salud propia. Dicho por-mor-de es el que se señala cuando advertimos que en el entramado respeccional que implica "el martillar", el Dasein, a final de cuentas, necesita protegerse para concretar su posibilidad de ser. Es así que, "la totalidad respeccional misma remonta, en último término, a un para-qué que ya no tiene ninguna condición respectiva más" (Heidegger 2012:105), sino que refiere al ser del Dasein mismo. Al respecto, Ramón Rodríguez menciona que el por-mor-de es un fin en sí mismo que "solo conviene al ser del existir" (Rodríguez 2003:55) ya que éste "es siempre forzosamente por mor de sí: lo que le mueve y hacia lo que se mueve es a construir su propio ser" (Rodríguez 2003:55). En este contexto, si volvemos al ejemplo del martillar, el "proteger la salud misma", entendido como por-mor-de que otorga sentido a la totalidad respeccional, presenta el carácter de "estar-en-el-mundo".

Hasta aquí se ha denominado remisión a la multiplicidad de sentidos de utilidad o "para qué" que se constituyen en una relación de "algo hacia algo". Pero esta estructura de remisión, en tanto que estructura de la comparecencia del mundo, desde ahora se llamará más específicamente significatividad.

Esta significatividad que se constituye en la remisión, no mienta que algo tiene valor o importancia particular para alguien, como, por ejemplo, el hecho de valorar un reloj heredado por un ser querido, del cual se afirma, coloquialmente, que sería "muy significativo para uno". También es preciso alejarse de aquellas comprensiones de significatividad como el "significado de una palabra", en el sentido de que un "término" remite a una cosa determinada de la cual éste sería el "nombre". Cuando Heidegger ocupa el término de significatividad, pretende, más bien, develar la estructura básica de la mundaneidad, es decir, "el ser de lo ente que llamamos mundo" (Heidegger 2006:254), entendida, en estricto rigor, como la "matriz de las relaciones remisionales" (Richardson 2003:56).

En este mismo sentido, cada "momento remisional", como, por ejemplo, el martillar un clavo o ajustar el techo, es un remitir, y el todo respeccional de esta remisión es, entonces, la significatividad. De este modo la familiaridad con la significatividad viene a ser la condición óntica que permite descubrir al ente que comparece en el mundo, por lo que es tal condición, la significatividad misma, la que da a conocer su "ensi" (Heidegger 2012:96). Es así que el mundo se hace "presente" desde la significatividad, es decir, en una relación del trato con el Dasein donde las cosas se revelan en lo que ellas mismas son, siempre en esta relación ocupada.

Ahora bien, luego de haber delimitado las nociones básicas acerca del Dasein y la mundaneidad del mundo, es necesario detenernos en aquello que le brinda a éste su sentido ontológico y trascendental, llamado por Heidegger cuidado. Esta estructura originaria del Dasein es la que nos permitirá comprender el sentido en el que la ocupación se mueve. Con esta revisión habremos finalizado el camino que nos prepara para acceder a una noción existencial del fenómeno de la ocupación.

\section{El cuidado como el ser del Dasein}

Heidegger denomina al ser del Dasein cuidado (Sorge). Ésta sería, por lo tanto, "la estructura unitaria trascendental" (Richardson 2003:88) que le brindaría un sentido ontológico al Dasein en cuanto tal. 
Al respecto, se puede decir que el existir ocupado siempre está afectado por el mundo, ya que cada vez que la ocupación se ejecuta, el mundo le incumbe, absorbido en la significatividad. En esta dinámica, el Dasein debe, entonces, procurar que este trato se concrete cada vez él siéndolo, por lo que este comportarse ocupado tiene el carácter de cuidar-se. Por lo tanto, el Dasein debe atender o cuidar que este despliegue circunspectivo se manifieste por-mor-de sí mismo. Es así que, "por cuanto el propio Dasein en sí mismo es cuidado, solo por eso es por lo que experimenta el mundo (...) en su significatividad" (Heidegger 2006:318), esto es, únicamente porque el Dasein es cuidado, puede experimentar la significatividad.

En este contexto, "el sentido fundamental de la actividad fáctica de la vida es el cuidado" (Heidegger 2002:35). Y el "cuidarse de" algo es ocuparse de ello, concretarlo, hacerlo. Por lo que cada ocupación que realicemos será ejecutada en el horizonte del cuidado, que cada vez buscará disponer de lo necesario para atender a su propia realización. De este modo, toda la trama remisional es un "cada vez" cuidar la concreción de los "para algo" que particularmente la componen, siempre en miras del por mor de, es decir, del último sentido que articula la significatividad. Por lo tanto, es el complejo de remisiones lo que constituye el mundo que el Dasein abre cuidándose de sí mismo.

Es de esta forma que logramos obtener el sentido unificador del Dasein, a saber, el cuidado, de manera que ahora éste, en cuanto ser-en-el-mundo, podría ser mejor comprendido entendiendo que "cuidarse" es tal en cuanto cuidarse "de lo entorno del mundo que aparece, demorarse en él" (Heidegger 2012:130). Esta expresión mienta todo aquello de lo que el existir debe ocuparse para ir concretando sus posibilidades de ser. Por ejemplo, cuando nos cuidamos de estudiar, es porque procuraremos hacer lo necesario para que logremos finalmente llevar esta actividad a cabo. Es así que cuidaremos de mantenernos saludables, procuraremos estar descansados, reuniremos los útiles necesarios, en el interior de un complejo remisional, como textos de estudio, mesa, lápices, luz apropiada, silla, etc., que nos permitan, finalmente, la posibilidad de estudiar. Todos estos modos particulares del ocuparse procuran, entonces, su propia concreción a través del cuidado. Es así que, de forma general, en la cotidianidad nos cuidamos del mundo en cada ocasión, por lo que "el mundo está ahí como algo de lo que ya siempre y de alguna manera nos cuidamos" (Heidegger 2002:35).

Ciertamente, lo que acabamos de exponer, en relación con el ser del Dasein, en tanto cuidado y su mundo, entendido como entramado remisional, ya nos orienta de mejor forma para entender al fenómeno de la ocupación como una estructura fundamental del existir.

\section{La ocupación como el carácter de trato del Dasein con el mundo}

Previo a centrarnos en la ocupación como un momento estructural del existir, resulta necesario diferenciar dicha comprensión con la noción de solicitud. Así, en el §26 de Ser y Tiempo, Heidegger habla acerca de la coexistencia con otros y el coestar cotidiano. En dicho apartado éste menciona que el estar-en-el-mundo también implicaría un coestar (Mitsein) y un coexistir (Mitdasein) con otros Dasein, ya que "en la misma medida en que el Dasein es 'ser en el mundo', el 'yo' no puede ser jamás pensado como un sujeto aislado, sin mundo y sin los otros" (Vigo 2006:63). Es así que en el trato ocupado con el mundo el Dasein no solo es "ser junto" (Vigo 2006:68) al ente intramundano "sino que también comparece el otro Dasein, en calidad de usuario, destinatario o beneficiario de aquello de lo que el trato práctico-operativo se ocupa de modo inmediato" (Vigo 2006:69). Dicho modo de comparecencia es lo que Heidegger llama "coexistir". De esta forma, la comprensión de estar-en-el-mundo no implica al "yo" como aislado, ajeno a la presencia de 
"otros". El sentido de comprensión de "los otros", para Heidegger, no mienta una consideración al modo de que éstos se encuentren fuera de mí. No se trata tampoco que se dispongan al modo de "personascosas", en el sentido de que estén meramente ahí en el mundo. Según los planteamientos de Heidegger, encontramos al "otro", por ejemplo, en el trabajo o dando un paseo, es decir, el encuentro con "los otros" acaece en un ocupado "estar-en-el-mundo" (Heidegger 2012:138).

Es así que cada uno de estos otros Dasein tiene el modo de ser de estar-en-el-mundo ocupándose circunspectivamente. Es aquí donde podemos entender que "el mundo del Dasein es un mundo en común [Mitwelt]" (Heidegger 2012:139). Y es de esta forma que el estar-en es, ciertamente, un "coestar" con otros, pero donde cada uno de ellos comparece, ante todo, circunspectivamente, esto es, ocupados en el mundo.

En palabras de Heidegger, podemos ver que "el ente en relación con el cual el Dasein se comporta en cuanto coestar, no tiene empero el modo de ser del útil a la mano, sino que es también un Dasein" (Heidegger 2012:141). Es así que, como el Dasein en estricto rigor no se puede "ocupar" de otro Dasein, el trato con éste es distinto al de la circunspección: es el de la solicitud (Fürsorge). Aquí Vigo traduce Fürsorge como 'procurar por' al modo de 'ser para' el otro, a diferencia del 'procurar de' o 'proveer' en el caso del Besorgen.

En este sentido, Rodríguez menciona que para referirnos a la presencia de los "otros", es necesario primero atenerse al fenómeno del mundo, aquel que en el contexto del Umwelt (mundo circundante), donde se está habitualmente ocupado, es donde se da la posibilidad de que se presenten los "otros" en cuanto usuarios, proveedores, etc. En este mismo contexto, la ocupación con el mundo "mediante el cual la vida se deja acaecer, concretándose como posibilidad, se posibilita, a su vez, la comparecencia del otro en el mismo horizonte de mi ocupación" (Johnson 2012:54). Desde esta última problemática es que se abordará el tema que aquí nos convoca, y que es la ocupación misma.

Ahora bien, Heidegger se refiere a ocupación como Besorgen. Aquí es necesario remitirnos a la diferencia entre Sorge o Sorgen (cuidado o cuidar) y Besorgen (ocupación). Según la nota 19 del traductor de Prolegómenos para una historia del concepto de tiempo, Jaime Aspiunza, se podría decir que Besorgen corresponde a "ocupación" y Sorgen a "pre-ocupación", "siempre que esta última se entienda no como aflicción o pena, sino en sentido literal como preocupación, o disposición para la ocupación" (Heidegger 2006:301), que refleja más cercanamente lo que Heidegger comprende como cuidado. Otro autor que comenta al respecto es Roberto Rubio, quien dice que la decisión terminológica que utiliza Heidegger para elegir la palabra Besorgen no se encuentra lo bastantemente justificada en su obra. Sin embargo, Rubio indaga en los usos no filosóficos del término, y destaca que se utiliza para expresar un "llevar a cabo", "procurarse algo" o "temer por algo". Al respecto, Rubio advierte que, tanto el uso filosófico como no filosófico convergen en que "son maneras de relacionarse con las cosas en un sentido eminentemente instrumental" (Rubio 2015:75), concluyendo que, en base a un uso filosófico del término, "mediante el trato instrumental con las cosas (ocupación) se consolida el vínculo con un mundo previamente dado en el sentido de la residencia [habitación] en un mundo que nos resulta familiar" (Rubio 2015:75).

En este contexto, es interesante observar cómo es que Heidegger proporciona ejemplos precisos de ocupaciones. Entre ellas figuran: "manejar algo, trabajar con algo, producir, fabricar y emplear algo, custodiar y extraviar algo, examinar, observar, disponer, emprender, terminar y abandonar algo" (Heidegger 2008:29). Como se podría intuir, atendiendo a estos ejemplos, es que ocupación pareciera ser 
aquello que "hacemos" todos los días. Ahora bien, es importante aclarar que el hecho de que parezca que es lo que "hacemos", no implica que entonces las ocupaciones sean meras "acciones" o "actos". Sus caracteres esenciales se encuentran en una articulación unitaria con las estructuras originarias del Dasein.

En este sentido, el mundo es el "con-qué" del trato de la ocupación. Y es en este trato ocupado con el mundo que el Dasein se encuentra siempre. Vigo menciona, al respecto, que "el Dasein se encuentra a sí mismo, por lo pronto, en y desde aquello de lo que en cada caso se ocupa" (Vigo 2006:70). En otras palabras, es en la ocupación que el mundo comparece, y no porque el mundo exista es que nos ocupamos. Es así que en el contexto de la ocupación y mundaneidad, Heidegger refiere que "para una ocupación que permanece en cada caso en su ámbito de actividad, lo mundano (lo que está presente en el mundo) comparece como algo que resulta 'útil para', como algo 'de importancia para', como algo 'que contribuye $a^{\prime}$. (...). Este ámbito de cosas que se presentan en el mundo tiene su orientación fija y una espacialidad propia. Los lugares y los puestos de trabajo se articulan en el curso y el rumbo que dicta la ocupación" (Heidegger 2008:30).

Recodemos que habíamos explicado que en la ocupación comparece el "útil", y que esta misma ocupación es la que le brinda el sentido de utilidad a éste, ya que: no se investiga su aspecto, sino que la relación genuina con ella es la de utilizarla; la herramienta queda absorbida en la remisión. Y ahí radica algo esencial: el ocuparse en cierto sentido aparta la vista de la cosa que la herramienta es, la cual no se halla primariamente presente en cuanto tal cosa, sino empleada en cuanto herramienta" (Heidegger 2006:239).

En este contexto, es diferente utilizar un cuchillo para cortar verduras que para destapar un frasco. Claramente su uso depende de la respectiva ocupación. Es, entonces, dicho trato ocupado en el mundo lo que le da el carácter de útil a un ente, y no su forma o sus características cuantificables y observables. La relevancia que aquí adquiere la ocupación es fundamental, ya que es la que va dictando el sentido de lo que cotidianamente tratamos como lo "a la mano", es decir, a nuestra disposición. Por lo tanto, ese mismo trato va dirigido hacia nosotros mismos, encaminándonos a nuestro poder-ser.

Además del trato ocupado en el mundo, no podemos olvidar que constantemente en este despliegue del Dasein se encuentran también cooriginariamente "los otros". Es así que "el mundo circundante deja comparecer a los otros que nos resultan inmediatamente conocidos y familiares; en la ocupación circunmundante, los otros están ya siempre ahí como aquellos con los que uno tiene que habérselas en la ocupación" (Heidegger 2008:35). Por lo que los otros comparecen solo en el ámbito de la ocupación. Por ejemplo, si hablamos de asear nuestro hogar: limpiamos la mesa que remite a los "invitados" que cenaron en ella o a los que diariamente la ocupan, también advertiremos que los útiles de aseo tuvieron que ser adquiridos por un "otro" que vendió los productos, al mismo tiempo que aquellos fueron fabricados por "otros", etc. Es de esta forma que solo en la ocupación se presenta la comparecencia de los "otros" que están coexistiendo (Mitdasein) en un mundo común (Mitwelt). En palabras de Heidegger: "El trato que nos mantiene ocupados discurre en el mundo circundante y los otros comparecen de entrada solo en este ámbito de la ocupación" (Heidegger 2008:36).

En este sentido, la ocupación es el carácter del trato del Dasein en el mundo, que sitúa y le brinda sentido a la trama remisional en tanto significatividad, y que además es en la ocupación en la que comparecen "los otros". Es por esta razón que podemos concluir que el mundo no es aquello que se nos presenta como un conjunto de cosas que se encuentran ahí delante de nosotros, sino que el mundo es aquel en el que el Dasein permanece ocupado. 
Es así que el rol de la ocupación en la analítica existencial del Dasein es fundamental, ya que sin ella no hay trato con el mundo. De hecho, no habría algo así como mundo, por lo que "el estar-siendo-en-elmundo ocupándose de él es el que en cuanto tal propicia que comparezca el mundo" (Heidegger 2006:212).

Ahora bien, en relación con los aspectos involucrados por la ocupación y el cuidado, se puede decir que "en el ocuparse del mundo, el Dasein se cuida de su propio ser en el mundo. El Dasein está siempre vuelto hacia algo que lo ha colocado en el cuidado" (Heidegger 2008:60). Esto quiere decir que en el ocuparse estamos cuidando cada vez que este ocuparse mismo se concrete, proyectivamente hacia un por mor de, esto es, que nos ocupamos de nosotros mismos y, al cuidarnos de nosotros, reafirmamos cada vez nuestra existencia.

Si la ocupación se mueve en el horizonte del cuidado, entonces, es la ocupación misma una de las estructuras ontológicas fundamentales del ser del Dasein. De esta manera, el Dasein ocupado se anticipa y proyecta por mor de sí mismo, ejecutando su ser, mientras se encuentra en su ahí, arrojado en su mundo, embebido en la trama remisional de la significatividad. Esta es la forma como el Dasein ocupado se mueve en el sentido del cuidado.

Pues bien, hasta el momento se han advertido los caracteres centrales de la ocupación como un existenciario. El hecho de que Heidegger la considere así, la involucra inmediatamente con las estructuras ontológicas que posibilitan el existir humano. Es de este modo que, en el contexto de una analítica existencial, la ocupación es un carácter esencial de las estructuras originarias del Dasein, donde el mundo es el "con qué" del trato ocupado. Dicho de manera concreta, el Dasein es necesariamente en la medida en que se ocupa de sí en su mundo. De esta forma, en el contexto de una analítica existencial, la ocupación permite que el ser humano despliegue su mundo y configure, en la práctica, su vida fáctica, la de "todos los días". Así, la ocupación sería la posibilidad más genuina de trato con el mundo.

Sin embargo, hay otro aspecto relevante a considerar aquí, a partir de una noción de ocupación como existenciario, y es que el ser humano y la ocupación no podrían ser considerados como "partes" del fenómeno, es decir, como elementos separados, que convivirían en una interacción constante. Al respecto, comprendimos que el Dasein, es decir, el "ser-en-el-mundo", presenta un carácter unitario, esto es, está constituido por momentos tales como: ocupación, significatividad, cuidado, etc. Sin embargo, todos ellos constituyen una enteridad. Es así que, no podríamos entender al ser humano como una cosa y a la ocupación como otra, externa a él. Es en este sentido que ser humano y ocupación dan cuenta de un mismo fenómeno, de una totalidad. De este modo, hemos comprendido que el Dasein tiene el carácter del ocuparse y que en la ocupación es donde se pueden obtener "los caracteres ontológicos más inmediatos y propios del mundo con el que tratamos" (Heidegger 2008:31).

Finalmente, es necesario destacar que la presente discusión busca centrarse en el fenómeno de la ocupación circunspectiva como un momento fundamental de la estructura del existir desde el pensamiento de Heidegger, en tanto recurso para profundizar la discusión en el campo de la terapia ocupacional, por lo que no fueron considerados aspectos como la caída, la temporización del cuidado, que nos da paso a la comprensión de la posibilidad de la muerte, la resolución y al poder-ser-sí-mismo, no porque no signifiquen aspectos relevantes en nuestro diálogo, sino que abren otras posibilidades de comprensión del fenómeno mismo de la ocupación que podrán ser desarrolladas en una siguiente discusión. 


\section{A modo de conclusión}

Pues bien, hasta el momento, se han revisado los caracteres centrales de la ocupación como un existenciario. Se ha comprendido que se trata de un momento constitutivo fundamental del Dasein que se despliega y trata con el mundo que él mismo es. Se ha comprendido, por otra parte, el movimiento de la ocupación en la totalidad remisional, es decir, cómo ésta le brinda el sentido de utilidad a los útiles a la mano, así como también cómo ésta los dispone en una relación recíproca entre sí. Hemos comprendido, entonces, que el Dasein tiene el carácter del ocuparse. Finalmente, hemos analizado a la ocupación como un carácter fundamental del existir humano.

Y luego de este análisis, ¿podríamos decir que no es que nosotros efectuemos ocupaciones, en el sentido de elaborar un producto, sino que más bien somos en la ocupación?

Si consideramos que la única posibilidad que tiene el ser humano de concretarse como tal, es ocupándose de sí mismo en el mundo, entonces, no existe otra manera de ser nosotros mismos si no es en la ocupación. De esta forma, podemos concluir que la ocupación, finalmente, somos nosotros mismos en estricto sentido. Comprender al ser humano en cuanto ocupación, es entender al ser humano en cuanto humano, inseparablemente de su mundo. Así, se dejarían de lado aquellas nociones de hombre y de ocupación, como dos elementos separados, que a veces se encuentran y otras no.

Es así que, a nuestro juicio, y desde lo expuesto desde Heidegger, cada ocupación "habla" acerca de lo que somos o de lo que queremos ser, en un sentido propiamente existencial, es decir, en nuestras propias vidas. Así, el escribir, el alimentarnos, el trotar o el descansar, dan cuenta de lo que cada ser humano es, y, al mismo tiempo, de lo que quiere o no, ser. Éste es el sentido que la ocupación le brinda al ser humano, considerándola como un carácter esencial de su existir en el mundo.

Ahora bien, luego del análisis ya desarrollado, se presenta un próximo desafío, esto es, intentar ahora comprender, desde la noción de ocupación en cuanto existenciario, lo que implicaría para la práctica de la terapia ocupacional. En este punto estaría en juego pensar el auténtico "para qué" de la profesión, aunque no resolviendo dicho problema preguntándonos qué es terapia ocupacional, sino, más bien, cómo ha de realizarse, ejercerse, la terapia ocupacional desde la consideración del ser humano en cuanto ocupación, en el sentido de la existencia humana misma.

Si comprendemos, en definitiva, que la ocupación somos nosotros, y a su vez, que ésta es la única forma con la que el ser humano cuenta para la concreción de sus posibilidades en el mundo, entonces, una nueva terapia ocupacional es posible. Nos referimos a una terapia ocupacional que se entienda a sí misma a partir de la idea de ocupación como aquello que le brinda la auténtica existencia al ser humano.

\section{Bibliografía}

Basso, L. 2014. Aportes para una interpretación de la estructura del Dasein de acuerdo a su carácter bidimensional. ARETÉ Revista de Filosofía 26(2): 273-293.

http://www.scielo.org.pe/pdf/arete/v26n2/a05v26n2.pdf

Cataldo, G. 2013. Existencia e historicidad, el problema de la identidad en Martin Heidegger. Ideas y Valores 62(153): 31-44. http://www.redalyc.org/articulo.oa?id=80929838002 
De Lara, F. 2008. El concepto de fenómeno en el joven Heidegger. Eidos 8: 234-256. http://www.redalyc.org/articulo.oa?id=85400812

Dastur, F. 2006. Heidegger y la cuestión del tiempo. Buenos Aires: Ediciones del Signo.

Guajardo, A. 2011. Prólogo, pp. 13-20. En: Grupo de Investigación Ocupación y Realización Humana. Ocupación: sentido, realización y libertad. Diálogos ocupacionales en torno al sujeto, la sociedad y el medio ambiente. Bogotá: Universidad Nacional de Colombia.

Heidegger, M. 2002. Interpretaciones fenomenológicas sobre Aristóteles. Madrid: Trotta.

Heidegger, M. 2006. Prolegómenos para una historia del concepto de tiempo. Madrid: Alianza.

Heidegger, M. 2008. El concepto de tiempo. Madrid: Herder.

Heidegger, M. 2012. Ser y tiempo. Madrid: Trotta.

Johnson, F. 2012. Lógica del objeto y lógica hermenéutica: el carácter existencial del ser y la nueva orientación del trabajo ontológico en el joven Heidegger. Studia Heideggeriana 2: 35-56.

Kielhofner, G. 2006. Fundamentos conceptuales de la terapia ocupacional. Buenos Aires: Ed. Médica Panamericana.

Morrison, R; Olivares, D. y Vidal, D. 2011. La filosofía de la ocupación humana y el paradigma social de la ocupación. Algunas reflexiones y propuestas sobre epistemologías actuales en terapia ocupacional y ciencias de la ocupación. Revista chilena de terapia ocupacional 11(2): 102-119. https://doi.org/10.5354/0719-5346.2011.17785

Richardson, W. 2003. Heidegger, through phenomenology to thought. New York: Fordham University Press.

Rodríguez, R. 2003. La hermenéutica del sí mismo en ser y tiempo en la filosofía como pasión. Madrid: Editorial Trotta.

Rubio, R. 2015. La mundaneidad del mundo en ser y tiempo de Martin Heidegger. Un comentario fenomenológico. Madrid: Tecnos.

Vigo, A. 2006. La recuperación crítica de la pregunta por el ser en Heidegger. Signos Filosóficos 8(15): 65104. http://www.redalyc.org/pdf/343/34301503.pdf

Wilcock, A. 2006. An occupational perspective of health. Boston: SLACK.

Recibido el 30 May 2018

Aceptado el $14 \mathrm{Jul} 2018$ 